wars and to ensure universal access of masks to all citizens. Rationing of surgical masks was implemented to prevent panic buying of masks, which would drain local supplies. The mask rationing system was delicately adjusted according to the production of masks and the amount required by healthcare workers, while ensuring that the entire population had adequate access (Fig. 1A).

The initial rationing system limited every person to 2 surgical masks per week. The purchase was tracked using the individual's national health insurance card-health insurance that covers $99 \%$ of residents. With the resumption of school classes on February 21, the purchase limit for surgical masks was increased to 4 masks per week for children (Fig. 1A). ${ }^{4}$ With the increased production of masks, the quota increased to 5 masks for children and 3 masks for adults per week. By the end of February, Taiwan was producing 5 million masks daily and had a substantial surplus of masks (Fig. 1B). ${ }^{4}$ As of April 9, 2020, the purchase quota was increased to 9 surgical masks per person per 2 weeks. The ban on the export of masks was lifted, and Taiwanese nationals can now send masks to relatives residing abroad. To help the rest of the world to battle the pandemic, Taiwan also exported 10 million masks to the United States, Europe, and its allies in April 2020. ${ }^{4}$

Since the outbreak, many Asian countries have recommended or mandated the use of surgical masks in the healthy general population. ${ }^{5}$ Previously, the US CDC recommended that masks should only be worn by healthcare workers, caregivers, or symptomatic individuals. Part of this rationale was that universal masking in the general population may limit the amount of masks available to healthcare settings. However, Taiwan's example illustrates that this supply problem may be overcome through a combination of policies such as increased mask production and rationing, and ensuring that the demand and supply of masks remain in balance (Fig. 1B).

Although the use of surgical masks in the healthy population has not been directly proven to reduce the spread of the coronavirus, it may provide source control and protect against asymptomatic transmission. ${ }^{5}$ Recent mechanistic studies have suggested that surgical masks may reduce the transmission of the coronavirus if worn by patients. ${ }^{6}$ Furthermore, a recent meta-analysis showed that masking practices may produce marginal reduction in transmission of respiratory virus in the community. ${ }^{7}$ At a population level, even marginal reduction in transmission may substantially slow the spread of the SARS-CoV-2 virus. Economically, mask interventions have been shown to be cost saving in a pandemic setting. ${ }^{8}$ Taiwan created a sufficient stockpile of masks for both the healthcare settings and the general population, and its example could serve as a model for other countries to learn from as we continue our fight against the COVID-19 pandemic.

Acknowledgments. None.

Financial support. No financial support was provided relevant to this article.

Conflicts of interest. All authors report no conflicts of interest relevant to this article.

\section{References}

1. Coronavirus disease 2019 (COVID-19): steps to prevent illness. Centers for Disease Control and Prevention website. https://www.cdc.gov/coronavirus/ 2019-ncov/about/preventiontreatment.html. Accessed April 17, 2020.

2. National Health Command Center. Taiwan Centers for Disease Control website [in Chinese]. https://www.cdc.gov.tw/En/Category/MPage/gL7bARtHyNdrDq882pJ9Q. Accessed April 17, 2020.

3. Wang CJ, Ng CY, Brook RH. Response to COVID-19 in Taiwan: big data analytics, new technology, and proactive testing. JAMA 2020;323: 1341-1342.

4. Central News Agency (CNA). Taiwan National News Agency website. https://focustaiwan.tw/. Accessed 17 April, 2020.

5. Feng S, Shen C, Xia N, Song W, Fan M, Cowling BJ. Rational use of face masks in the COVID-19 pandemic. Lancet Resp Med 2020;8:434-436

6. Leung NHL, Chu DKW, Shiu EYC, et al. Respiratory virus shedding in exhaled breath and efficacy of face masks. Nat Med 2020;26: 676-680.

7. Xiao J, Shiu EYC, Gao H, et al. Nonpharmaceutical measures for pandemic influenza in nonhealthcare settings-personal protective and environmental measures. Emerg Infect Dis 2020;26:967-975.

8. Mukerji S, MacIntyre CR, Newall AT. Review of economic evaluations of mask and respirator use for protection against respiratory infection transmission. BMC Infect Dis 2015;15:413-413.

\title{
The feasibility of generalized face mask usage during the COVID-19 pandemic: a perspective from Latin America
}

\author{
Daniel Moreno Soto BSc ${ }^{1}$ (1), Walter D. Cardona Maya $\mathrm{PhD}^{1}$ (1), Esteban Londoño Agudelo $\mathrm{MPH}^{2,3}$ (1) and \\ Julio C. Bueno-Sánchez $\mathrm{PhD}^{1}$ (i) \\ ${ }^{1}$ Reproduction Group, Medical School, University of Antioquia, Medellín, Colombia, ${ }^{2}$ Faculty of Medicine, CES University, Calle 10A \#22-04, Medellín, Colombia and \\ ${ }^{3}$ Institute of Tropical Medicine, Antwerp B-2000, Belgium
}

\footnotetext{
Author for correspondence: Daniel Moreno Soto, E-mail: dm60zyjo@studserv. uni-leipzig.de

Cite this article: Moreno Soto D, et al. (2021). The feasibility of generalized face mask usage during the COVID-19 pandemic: a perspective from Latin America. Infection Control \& Hospital Epidemiology, 42: 245-246, https://doi.org/10.1017/ice.2020.227
}

To the Editor-Standardized medical masks, such as surgical or procedure masks and face-piece respirators, including N95 and N99, are an indispensable part of the protective personal equipment (PPE) during infectious outbreaks. These masks are intended for single use by healthcare personnel during high-risk procedures. ${ }^{1,2}$ However, the reuse of masks, as well as the extension of the usage to the general population, commonly arise during a crisis like the 
current COVID-19 pandemic. Official recommendations about this generalized usage have varied during the outbreak and according to the available evidence. The World Health Organization currently recommends restricting medical masks to healthcare workers and people with respiratory symptoms or caring for a person suspected of SARS-CoV-2 infection, along with diligent compliance to other infection prevention and control measures, such as hand hygiene and social distancing. ${ }^{1}$ However, new evidence seems to indicate that the use of facial protection by the general population may help to prevent the overall transmission of SARS-CoV-2. ${ }^{3}$

As the pandemic advances in the Americas, with $1,857,509$ confirmed cases and 111,942 deaths as of May 15, 2020, ${ }^{4}$ some Latin American countries, such as Colombia, ${ }^{5}$ have established measures forcing the general population to wear facial protection in public settings. The extent of the benefit of such measures is still hard to assess, but as a precautionary principle, it could be preferable to use any kind of mask in case it entails some improvement. However, such a premise would only hold if there is a fair trust that this setting will most likely not generate additional risks during the outbreak. Briefly, the measure must be applied under some parameters to be safe.

First, mass use of facial protection requires that a sufficient and sustained supply of medical masks for healthcare staff is available.

Second, in the recurring scenario of insufficient supply due to shortage, the necessity of disinfection processes for lengthy usage or reuse of face masks must be acknowledged. The careless extension of intended operation limits could lead to self-contamination. Recent evidence shows that the virus might be particularly stable on the surface of surgical masks (one of the currently most widely used face mask types) for as long as 7 days. $^{6}$ There are several feasible alternatives for disinfecting face masks, with some type of heat and ultraviolet germicidal irradiation standing out among them. These methods have been shown to successfully inactivate the virus ${ }^{6-8}$ without causing significant loss of mask functionality, ${ }^{9}$ and they are already being used in healthcare facilities, either by using autoclaves or by repurposing incubators, idle cabins, or whole rooms with ultraviolet type C (UVC) light bulbs.

Third, the accessibility of the general population to mask disinfection methods must be assessed. Chemical methods of disinfection, such as soap, ethanol, or sodium hypochlorite, are not viable because they would remove the electrostatic charge of the mask, impairing its filtration capacities. ${ }^{10}$ An alternative for mask disinfection is devices crafted to work with UVC or heat, and for which building instructions using commercially available materials can be found online for free. However, a large portion of the population will not have access to these devices; therefore, the use of washable cloth face covering should be favored; it is the current trend in some countries.

Fourth, independent of the type of masks used, people must be systematically educated about its proper use and actual capabilities (eg, to change washable face masks every 3 hours with a clean one and maintain social distancing).

Overall, the application of mass masking has an intrinsic risk that must be evaluated. Latin American countries are particularly vulnerable because they are in general not self-sufficient to ensure an adequate procurement of masks during the outbreak, which will pose a threat to the safety of already vulnerable healthcare personnel, and the low income of the population will probably result in excessive reuse of masks. Moreover, this region has no prior experience with mask use, unlike many Asian countries, such as China, South Korea, or Singapore, which are usually the major reference for masking measures. Ultimately, sociopolitical constraints may prompt a premature end to social distancing, and negligent face mask usage could induce a false sense of security based on insufficient information.

\section{Acknowledgments. None.}

Financial support. This research did not receive any specific grant from funding agencies in the public, commercial, or not-for-profit sectors.

Conflicts of interest. All authors state that they have no conflict of interest regarding this study.

\section{References}

1. Advice on the use of masks in the community, during home care and in healthcare settings in the context of the novel coronavirus (2019-nCoV) outbreak. World Health Organization website. https://www.who.int/publications-detail/ advice-on-the-use-of-masks-in-the-community-during-home-care-and-inhealthcare-settings-in-the-context-of-the-novel-coronavirus-(2019-ncov)outbreak. Published April 6, 2020. Accessed May 8, 2020.

2. Recommended guidance for extended use and limited reuse of N95 filtering face-piece respirators in healthcare settings. Centers for Disease Control and Prevention website. https://www.cdc.gov/niosh/topics/ hcwcontrols/recommendedguidanceextuse.html. Published 2019. Accessed April 2, 2020.

3. Leung NHL, Chu DKW, Shiu EYC, et al. Respiratory virus shedding in exhaled breath and efficacy of face masks. Nat Med 2020 Apr 3 [Epub ahead of print]. doi: 10.1038/s41591-020-0843-2.

4. Coronavirus disease (COVID-19). Pan American Health Organization website. https://www.paho.org/en/topics/coronavirus-infections/coronavirusdisease-covid-19. Published 2020. Accessed April 18, 2020.

5. El uso de tapabocas se hace obligatorio en el sistema de transporte público [in Spanish]. Ministerio de Salud y Protección Social - República de, Colombia. https://www.minsalud.gov.co/Paginas/El-uso-de-tapabocas-sehace-obligatorio-en-el-sistema-de-transporte-publico.aspx. Published 2020. Accessed April 10, 2020.

6. Chin A, Chu J, Perera M, et al. Stability of SARS-CoV-2 in different environmental conditions. Lancet 2020 Apr 2 [Epub ahead of print]. doi: 10.1016/S2666-5247(20)30003-3.

7. Duan SM, Zhao XS, Wen RF, et al. Stability of SARS coronavirus in human specimens and environment and its sensitivity to heating and UV irradiation. Biomed Environ Sci 2003;16:246-255.

8. Darnell MER, Subbarao K, Feinstone SM, Taylor DR. Inactivation of the coronavirus that induces severe acute respiratory syndrome, SARS-CoV. J Virol Methods 2004;121:85-91.

9. Bergman MS, Viscusi DJ, Heimbuch BK, Wander JD, Sambol AR, Shaffer RE. Evaluation of multiple (3-cycle) decontamination processing for filtering facepiece respirators. J Eng Fiber Fabr 2010;5:33-41.

10. Anesthesia Informatics and Media Lab. Addressing COVID-19 face mask shortages. Stanford Medicine website. https://stanfordmedicine. app.box.com/v/covid19-PPE-1-1. Updated March 22, 2020. Accessed April 2, 2020. 